\title{
Cognitive behaviour therapy or temazepam, or both, improved short term outcomes for older adults with persistent insomnia
}

\author{
Morin CM, Colecchi C, Stone J, et al. Behavioral and pharmacological therapies for late-life insomnia. A randomized controlled \\ trial.JAMA 1999 Mar 17:281:991-9.
}

\section{Question}

In older adults with persistent insomnia, is cognitive behaviour therapy $(\mathrm{CBT})$ or temazepam, alone or together, effective for improving sleep patterns and habits?

\section{Design}

Randomised, placebo controlled, 8 week trial with follow up at 3, 12, and 24 months.

\section{Setting}

The outpatient clinic of a Canadian academic medical centre.

\section{Patients}

78 older adults (mean age 65 y, $64 \%$ women, $90 \%$ white, average duration of insomnia $17 \mathrm{y}$ ) who were aged $\geq 55$ years, and had sleep onset or maintenance insomnia for $>6$ months, and $\geq 1$ negative effects of insomnia during waking hours. Exclusion criteria were insomnia caused by disease or medication, sleep apnea, regular use of hypnotic or psychotropic medication, current psychotherapy, presence of major depression or other serious psychiatric conditions, or confirmed cognitive impairment. Follow up ranged from $92 \%$ at 8 weeks to $63 \%$ at 2 years.

\section{Intervention}

18 adults were allocated to CBT alone, 20 to temazepam alone, 20 to both, and 20 to placebo. CBT was designed to change habits and beliefs around sleep by using 8 weekly 90 minute small group sessions with behavioural, cognitive, and educational components. Individual action plans were implemented. Temazepam treatment was started at $7.5 \mathrm{mg} /$ night and was increased to $30 \mathrm{mg} /$ night as needed. All treatments were for 8 weeks.

\section{Main outcome measures}

Sleep diaries, polysomnography, and sleep impairment index.

\begin{abstract}
Main results
Groups receiving CBT improved more initially than those receiving temazepam or placebo as measured by sleep diaries (table). Polysomnography showed that sleep improved in the short term in all active treatment groups; the combined treatment group improved more than the others. CBT alone maintained improvement in sleep measures better than combined treatment, which was better than temazepam alone, although follow up beyond 8 weeks was $<80 \%$.
\end{abstract}

\section{Conclusion}

Cognitive behaviour therapy or temazepam, or both, improved short term outcomes in older adults with persistent insomnia.

Patients achieving $>85 \%$ sleep efficiency (time asleep/time in bed) with cognitive behaviour therapy $(C B T)$ or temazepam, or both, in older adults with persistent insomnia after 8 weeks of treatment*

\begin{tabular}{lllll}
\hline Group & Treatment & Placebo & RBI (95\% CI) & NNT (CI) \\
\hline CBT & $56 \%$ & $22 \%$ & $150 \%(3.8$ to 561$)$ & 3 (2 to 96$)$ \\
Temazepam & $47 \%$ & $22 \%$ & $112 \%(-17$ to 477$)$ & Not significant \\
Both & $68 \%$ & $22 \%$ & $208 \%(36$ to 689$)$ & 3 (2 to 7) \\
\hline
\end{tabular}

*Abbreviations defined in glossary; RBI, NNT, and CI calculated from data in article.

Source of funding: National Institute of Mental Health Clinical Research Center.

For correspondence:Dr C M Morin, Université Laval, Ecole de Psychologie, Pavillion FAS, Sainte-Foy, Quebec G1K 7P4, Canada.Fax +1 4186565152.

Abstract and commentary also published in ACP Journal Club.

\section{Commentary}

This exciting, exquisitely done study from an academic medical centre has implications for frontline clinicians. Firstly, many older adults with sleep problems have underlying problems that should be treated directly: disease, medication that causes insomnia, depression, psychiatric disorders, sleep apnea, periodic limb movements, and inability to decrease the dose of a presently taken hypnotic. These patients (85 of 168 screened) were excluded from this study.

Secondly, long term control of later life sleep problems is probably best achieved through a psychological educational approach rather than medicines. Even though this study implication is based on results with $<80 \%$ follow up, I feel that this approach is sensible and justified.
Thirdly, short term insomnia may be treated with similar efficacy with education or medicines, or both. This trial, however was not large enough to address important concerns about benzodiazepine use including falls, cognitive impairment, and dependence.

One should be aware that the extensive CBT classes used by the authors are not generally available. Teaching of sleep hygiene has long been encouraged as the preferred method for promoting healthy sleep. An aid for teaching sleep hygiene is the patient education page in the same issue of $J A M A^{1}$; this aid, the article, and the accompanying editorial $^{2}$ are also available on the American Medical Association's website (http://jama.ama-assn.org/issues/ v281n11/toc.html). Unfortunately, substi- tuting the teaching of sleep hygiene for CBT and expecting similar results involves a leap of faith. I would like to see a study using an abbreviated form of CBT, such as the teaching of sleep hygiene. This teaching would probably be more practical for busy clinicians who are not psychiatrists. For now we can discuss the common sense principles of CBT with our patients as outlined in the article.

Robert Lebow, MD University of Massachusetts/Harrington Southbridge, Massachusett, USA

1 JAMA patient page: insomnia. JAMA 1999; 281:1056.

2 Reynolds CF, Buysse DJ, Kupfer DJ. Treating insomnia in older adults: taking a long-tern view [editorial]. JAMA 1999;281:1034-5. 